УДК 577.352 .54

(C) 2012

Волков С. І., кандидат хімічних наук, Бульба С. М., асистент

Полтавська державна аграрна академія

Смердова Т. А., кандидат технічних наук

Національний університет «Львівська політехніка»

\title{
АНАЛІЗ ЗБУДЖЕННЯ БІОЛОГІЧНОЇ СТРУКТУРИ ЕЛЕКТРИЧНИМИ ІМПУЛЬСАМИ
}

\section{Рецензент - доктор технічних наук, професор, академік Академії інженерних наук Украӥни \\ A. А. Смердов}

Запропонована модель і проведений аналіз електричних властивостей біологічних тканин, який дає можливість враховувати комплексний опір живої системи і поляризацію клітинних мембран внаслідок роботи іонних насосів. Одержане диференційне рівняння, щзо пов 'язує напругу збудження з частотою змінного струму і дає змогу теоретично обтрунтувати закон часу подразнення. На основі запропонованої моделі розглянуті випадки подразнення для прямокутного імпульсу та змінної синусоїдальної вхідної напруги.

Ключові слова: мембрана, електричний імпульс, поляризачія, потенціал дії, потенціал спокою, закон часу дї̈ подразнення.

Постановка проблеми. Електричні властивості біологічних тканин мають певні особливості, які пов'язані 3 наявністю в них клітинних мембран. Існують еквівалентні електричні схеми, що враховують наявність у біологічних тканинах клітин мембран [1-3, 5]. При цьому мембрану розглядають як конденсатор із великим струмом витоку. Недоліком таких схем є те, що в них не враховується поляризація клітинних мембран за рахунок активного транспорту іонів через мембрану (іонні насоси).

Аналіз основних досліджень і публікацій, у яких започатковано розв'язання проблеми. Знаходження пасивних електричних характерис- тик біологічних систем дає значну інформацію про їх функціонування. Зокрема дослідження дисперсії опору дозволяє робити висновки щодо інтенсивності обмінних процесів у тканині $[1,3]$. Вимірювання імпедансу (метод реографіi) [4] використовують у медицині для оцінки стану кровообігу (периферійного, окремих органів тощо).

Електричну модель біологічної тканини розглядають частіше всього у вигляді схеми, що представлена на рис. 1 [3].

Вказана схема дає змогу пояснити комплексний характер опору живої системи, тобто наявність, окрім активної, ще й ємнісної складової опору. За допомогою аналізу роботи цієї системи стає зрозумілою залежність опору біологічних систем від частоти та яким чином дана залежність пов’язана з інтенсивністю обмінних процесів.

Однак ця модель не враховує поляризацію клітинних мембран, що виникає за рахунок активного транспорту іонів. Справа в тім, що крім пасивного транспорту (дифузія, осмос) відбувається активний транспорт іонів через мембрану. До активного транспорту належить сполучений транспорт іонів калію і натрію, так званий $\mathrm{K}^{+} \mathrm{Na}^{+}$ - насос. За рахунок енергії АТФ, внаслідок роботи цього насосу, всередину клітини вводяться іони калію, а з клітини виводяться іони натрію.

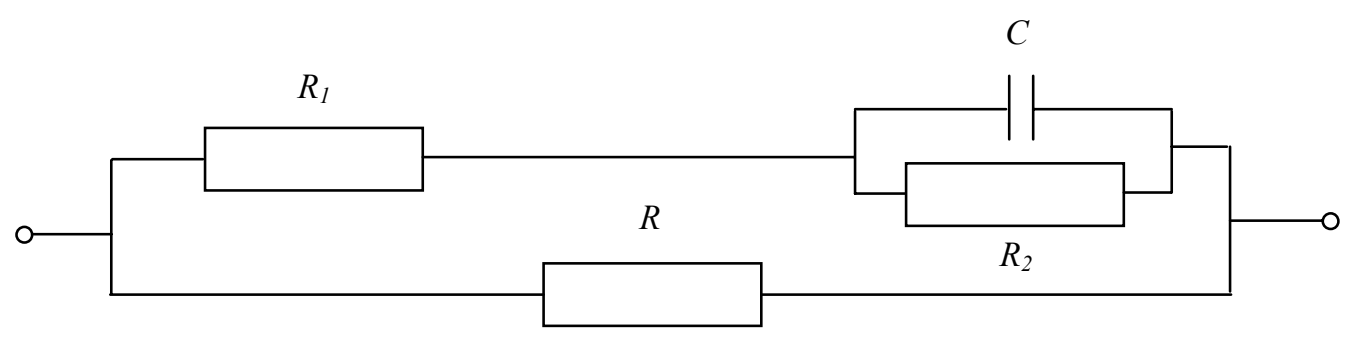

Рис. 1. Еквівалентна електрична схема біологічної тканини.

$R$ - опір міжкклітинного середовища, $R_{1}$ - опір вмісту клітини, $R_{2}$ - активний опір мембран, C-смність мембран 
Цей процес протікає у відношенні 2:3, тобто на три іони натрію, що виводяться 3 клітини, всередину іiі вводиться тільки два іони калію. Внаслідок цього клітина буде мати від'ємний (по відношенню до оточуючого середовища) електричний заряд, а мембрана поляризована. Від'ємні заряди зосереджені на внутрішній стороні мембрани, а позитивні - на зовнішній. Виникаючий при цьому трансмембранний потенціал називається потенціалом спокою $\varphi_{c n}$. Для незбудженої нервової клітини ця величина набирає значення від -60 до -70 мВ. Таким чином, у стані спокою мембрана являє собою конденсатор, заряджений внаслідок роботи іонних насосів до величини потенціалу спокою.

Мета досліджень. Метою досліджень $є$ вдосконалення відомої електричної моделі біологічних тканин з урахуванням процесу поляризації клітинної мембрани за рахунок роботи іонних насосів.

Методи досліджень. В основі розробки та дослідження моделі біологічної тканини використовувалися метод аналізу електричних властивостей цих тканин, метод аналогії з уже розробленими моделями та метод індукції - при виведенні загального диференційного рівняння.

Результати досліджень. 3 електричної точки зору, іонний насос можна розглядати як джерело постійного струму, в якому за допомогою зовнішніх (не електричних) сил утворюється різниця потенціалів по різні сторони клітинної мембрани. Джерело постійного струму характеризується певними значеннями електрорушійної сили та внутрішнього опору. 3 урахуванням сказаного, запропонована еквівалентна електрична схема біологічної тканини має вигляд, представлений на рис. 2.

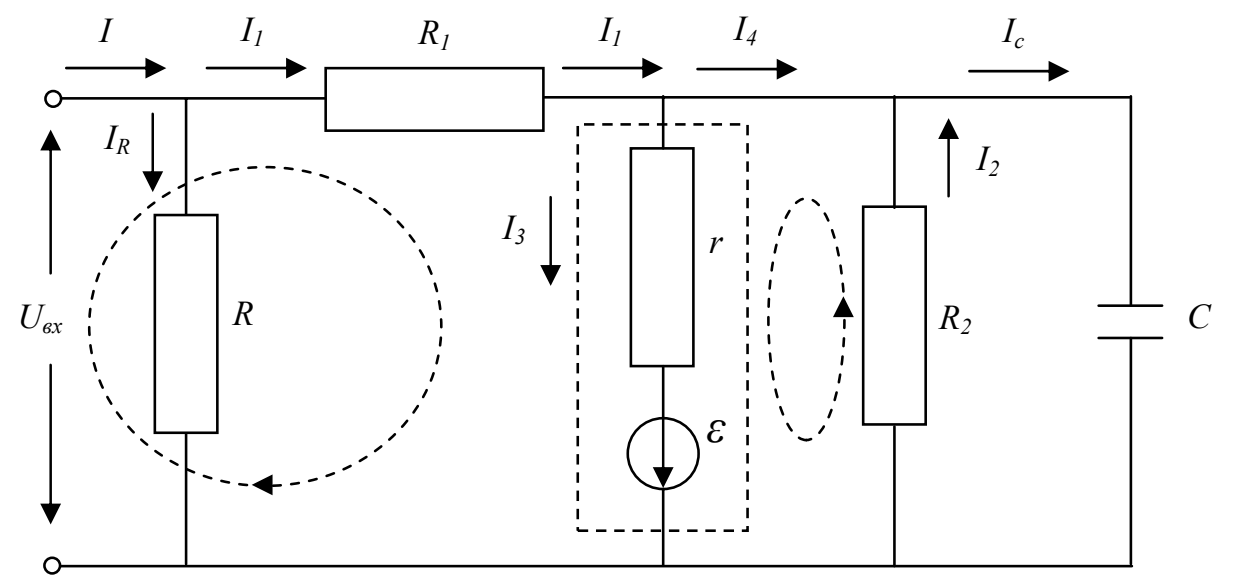

Рис. 2. Удосконалена еквівалентна електрична схема біологічної тканини: $\varepsilon$-електрорушійна сила, $r$ - внутрішній опір

Запропонована схема відрізняється від попередньої наявністю внутрішнього джерела з електрорушійною силою $\varepsilon$ і внутрішнім опором $r$.

Співвідношення між струмами і напругами схеми визначаються системою рівнянь, що грунтуються на законах Кірхгофа:

$$
\begin{aligned}
& I-I_{1}-I_{2}=0 ; \\
& I_{1}-I_{3}-I_{4}=0 ; \\
& I_{4}+I_{2}-I_{C}=0 ; \\
& U_{6 x}+\varepsilon=I_{1} R_{1}+I_{3} r ; \\
& \varepsilon=I_{2} R_{2}+I_{3} r ; \\
& I_{C}=C \frac{d U_{C}}{d t} ; \\
& -U_{C}=I_{2} R_{2} ; \\
& U_{B x}=I_{R} R .
\end{aligned}
$$

У цих рівняннях $U_{C}-$ напруга на конденсаторі, а $U_{b x}-$ вхідна напруга.

Розглянемо деякі окремі випадки аналізу схеми. 
Якщо напруга на вході схеми не дорівнює нулю, то розв'язок системи рівнянь, по відношенню до $U_{C}$, приводить до звичайного неоднорідного диференційного рівняння, яке має вигляд:

$$
\mathrm{CR}_{1} \frac{\mathrm{dU}_{\mathrm{C}}}{\mathrm{dt}}+\mathrm{U}_{\mathrm{C}}\left(\frac{\mathrm{R}_{1}}{\mathrm{r}}+\frac{\mathrm{R}_{1}}{\mathrm{R}_{2}}+1\right)=\mathrm{U}_{\mathrm{Bx}}-\varepsilon\left(\frac{\mathrm{R}_{1}}{\mathrm{r}}+1\right) .
$$

Введемо позначення:

$$
\left(\frac{R_{1}}{r}+\frac{R_{1}}{R_{2}}+1\right)=a,
$$

$$
C R_{1}=\tau \text {. }
$$

Тоді рівняння (2) можна записати у вигляді:

$$
\tau \frac{d U_{C}}{d t}+a U_{C}=U_{\text {вx }}-\varepsilon\left(\frac{R_{1}}{r}+1\right) .
$$

У випадку, коли зовнішнього впливу немає $\left(U_{b x}=0\right)$, напруга на конденсаторі відповідає напрузі на клітинних мембранах $\varphi_{c n}$, але не співпадає з нею:

$\varphi_{c n}=-\frac{\varepsilon}{a}\left(\frac{R_{1}}{r}+1\right)$.

Рівняння (5) може бути представлене у вигляді:

$$
\frac{d y}{d t}+P y=Q
$$

де $y=U_{C}, P=\frac{a}{\tau}, Q=\frac{U_{B x}}{\tau}-\frac{\varepsilon}{\tau}\left(\frac{R_{1}}{r}+1\right)$.

Розв'язок рівняння (7) за умови, коли $P i Q$ є величинами постійними або залежать тільки від $t$, має вигляд:

$$
y=e^{-\int P d t}\left(Q e^{\int P d t} d t+A\right)
$$

де А - стала інтегрування.

У випадку прямокутного імпульсу

$$
U_{C}=\varphi_{c n}+\frac{U_{0}}{a}\left(1-e^{-\frac{a}{\tau} t}\right)
$$

де $U_{0}$ - амплітуда імпульсу.

Коли час $t$ прямує до нескінченності, що відповідає постійному струмові, то напруга на конденсаторі приймає значення:

$$
U_{\infty}=\varphi_{c n}+\frac{U_{B x}}{a} .
$$

Для збудливих тканин, до яких належать, зокрема, нервова і м'язова, ситуація суттєво ускладнюється за дії на ділянку клітини подразника великої сили. При досягненні на клітинній мембрані напруги, що відповідає пороговому значенню, тобто коли поляризація мембрани досягає порогового значення, величина якого для нервових клітин має значення від -40 до -50 мВ, у мембрані відкриваються іонні канали («пробій» мембрани), відбувається ï̈ деполяризація й формується потенціал дії. Тривалість цього процесу до відновлення потенціалу спокою є величиною порядку декілька мілісекунд. У цей час система не реагує на дію подразника (фаза рефрактерності).

Таким чином, при досягненні певної напруги на конденсаторі схеми (рис. 2) $U_{C}=\varphi_{n}$, виникає збудження тканини (потенціал дії). Процес початку формування потенціалу дії схематично показаний на рис. 3. 


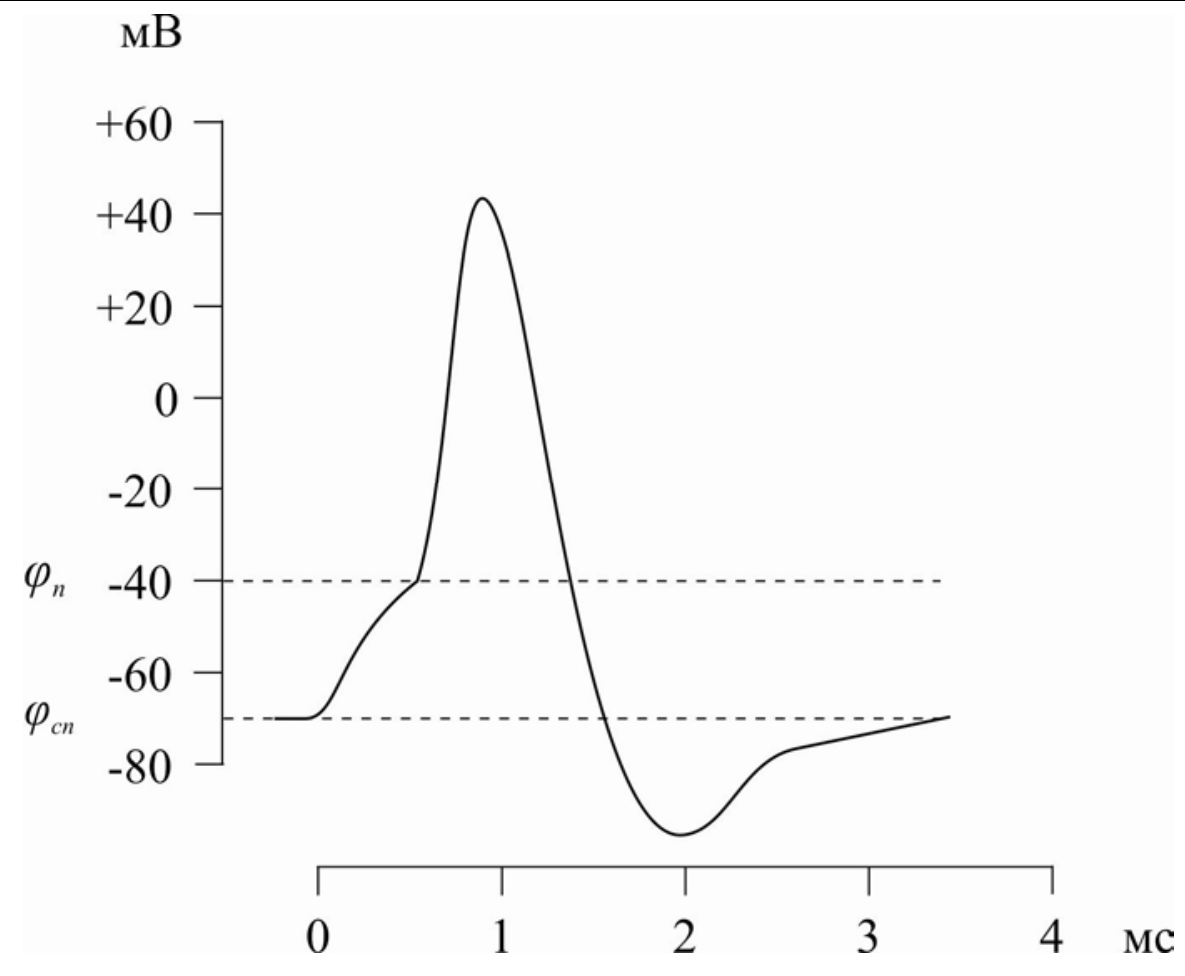

Рис. 3. Початок виникнення потенціалу дії

Якщо позначити напругу на вході схеми, при якій виникає збудження, як $U_{3 б}$, то з рівняння (9) можна визначити цю величину.

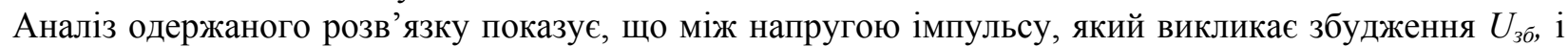
його тривалістю існує зв'язок:

$$
U_{3 \sigma}=\frac{a\left(\varphi_{n}-\varphi_{c n}\right)}{1-e^{-\frac{a}{\tau} T}},
$$

де $T$ - тривалість імпульсу.

Коли $T$ прямує до нескінченності (постійна напруга), то $U_{\text {зб }}=a\left(\varphi_{n}-\varphi_{c n}\right)$ (реобаза).

Таким чином, запропонована модель дає змогу теоретично обгрунтувати закон часу дії подразнення. Зауважимо, що одержаний математичний вираз відрізняється від емпіричного виразу, широко відомого закону Гоорвега-Вейса-Лапіка.

Відомо, що наслідком закону часу подразнення $є$ те, що струми високої частоти мають значення напруги більше порогового (реобаза) не викликають збудження тканини. Розглянемо випадок змінної синусоїдальної вхідної напруги на основі уявлень запропонованої моделі. В цьому випадку рівняння (5) набуде вигляду:

$$
\tau \frac{d U_{C}}{d t}+a U_{C}=U_{\text {вx }}+\varepsilon\left(\frac{R_{1}}{r}+1\right) .
$$

Розв'язок лінійного диференційного рівняння першого порядку (12) має вигляд:

$$
\begin{aligned}
& U_{C}=\frac{1}{\tau} e^{-\frac{a}{\tau} t}\left(\int Q e^{\frac{a}{\tau} t} d t+A\right), \\
& \text { де } Q=U_{0} \sin \omega t-\varepsilon\left(\frac{R_{1}}{r}+1\right)
\end{aligned}
$$

$A$ - стала інтегрування. 
Знаходження інтеграла $\int Q e^{\frac{a}{\tau} t} d t$ здійснюється за частинами. Остаточний вираз розв'язку рівняння (12) має вигляд:

$$
U_{C}=\left(\varphi_{c n}+\frac{\frac{U_{0}}{\tau}}{\left(\frac{a}{\tau}\right)^{2}+\omega^{2}}\left(\frac{a}{\tau} \sin \omega t-\omega \cos \omega t\right)\right)
$$

3 аналізу одержаного розв'язку видно, що напруга на конденсаторі змінюється за гармонійним законом відносно значення $\varphi_{c n}$. При цьому амплітуда і фаза коливань відрізняються від відповідних величин вхідної напруги. Згідно з формулою (14), амплітуда коливань напруги на конденсаторі $U_{0 C}$ дорівнює:

$$
U_{0 C}=\frac{\frac{U_{0}}{\tau}}{\left(\frac{a}{\tau}\right)^{2}+\omega^{2}} \sqrt{\left(\frac{a}{\tau}\right)^{2}+\omega^{2}}
$$

Як і у випадку прямокутного імпульсу, при досягненні на конденсаторі напруги $\varphi_{n}$, формується потенціал дії й виникає збудження тканини. Використовуючи формули (14) i (15), можна визначити напругу на вході схеми $U_{3 \sigma}$, за якої відбувається збудження. Для виникнення потенціалу дії (в умовах, що розглядаються) необхідно, щоб виконувалась умова:

$$
\left|\varphi_{c n}\right|-\frac{\frac{U_{0}}{\tau}}{\left(\frac{a}{\tau}\right)^{2}+\omega^{2}} \sqrt{\left(\frac{a}{\tau}\right)^{2}+\omega^{2}} \leq \varphi_{n} .
$$

Таким чином, напруга збудження залежить від частоти струму за законом, що визначається формулою:

$$
U_{\text {зб }}=\tau \sqrt{\left(\frac{a}{\tau}\right)^{2}+\omega^{2}}\left(\varphi_{n}-\varphi_{c n}\right) .
$$

У випадку постійного струму, коли $\omega \rightarrow 0$, величина $U_{3 б}$ приймає вже відоме значення реобази:

$$
U_{p}=a\left(\varphi_{n}-\varphi_{c n}\right) \text {. }
$$

\section{Висновки:}

1. Запропонована електрична модель біологічної тканини, що враховує наявність поляризації клітинних мембран внаслідок роботи іонних насосів.

2. Аналіз запропонованої моделі дає змогу визначити час подразнення тканини при дії зовнішнього збудження і представити залежність між напругою і частотою збуджуючого змінного струму.

\section{БІБЛІОГРАФІЯ}

1. Гордеев А. С. Электрофизические критерии качества плодов // Механизация и электрификация сельского хозяйства. - 1998. - №7. - С. 10-16.

2. Губанов Н. И., Утепбергенов А. А. Медицинская биофизика. - М. : Медицина, 1978. - 330 с. 3. Деркач М. П. Основи біофізики. - Львів : Видво Львівського університету, 1967. -278 с.
4. Тихомиров А. М. Импеданс биологических тканей и его применение в медицине. - М. : Российский государственный медицинский университет, 2006. - 12 c.

5. Leslie A. Geddes. Accuracy Limitations of Chronaxie Values // Transaction on biomedical engineering. - 2004. - Vol. 51. №1. - P. 176-179. 